Journal for ImmunoTherapy of Cancer

\title{
PD-1 inhibitor inducing exosomal miR- $34 a-5 p$ expression mediates the cross talk between cardiomyocyte and macrophage in immune checkpoint inhibitor-related cardiac dysfunction
}

\author{
Wenzheng Xia, ${ }^{1,2}$ Hanbin Chen, ${ }^{3}$ Didi Chen, ${ }^{3}$ Yijia Ye, ${ }^{3}$ Congying Xie, ${ }^{3}$ \\ Meng $\mathrm{Hou}$ (iD ${ }^{3}$
}

To cite: Xia W, Chen $\mathrm{H}$, Chen D, et al. PD-1 inhibitor inducing exosomal miR-34a-5p expression mediates the cross talk between cardiomyocyte and macrophage in immune checkpoint inhibitor-related cardiac dysfunction. Journal for ImmunoTherapy of Cancer 2020;8:e001293. doi:10.1136/ jitc-2020-001293

- Additional material is published online only. To view please visit the journal online (http://dx.doi.org/10.1136/jitc2020-001293).

WX, HC and DC contributed equally.

CX and $\mathrm{MH}$ contributed equally. WX, $\mathrm{HC}$ and $\mathrm{DC}$ are joint first authors.

Accepted 24 September 2020

Check for updates

(C) Author(s) (or their employer(s)) 2020. Re-use permitted under CC BY-NC. No commercial re-use. See rights and permissions. Published by BMJ.

For numbered affiliations see end of article.

Correspondence to Dr Meng Hou;

244517813@qq.com

Professor Congying Xie; wzxiecongying@163.com

\section{ABSTRACT}

Background Immune checkpoint inhibitors (ICls) have been an important therapeutic advancement in the field of cancer medicine. Recent reports provided greater insights into the cardiovascular adverse events, which prohibited the use of ICls. Cardiovascular adverse events occur in different forms, such as myocarditis and cardiomyopathy, myocardial fibrosis, heart failure and pericardial disease. Cardiac aging overlapped with the occurrence of some cardiac diseases. Exosomes mediate cell-cell cross talk in cardiac diseases by transferring a variety of biomolecules, including microRNAs (miRs). miR-34a-5p is a well-known miR associated with the cardiac senescence. This study aimed to investigate whether cardiovascular adverse effects of the programmed cell death 1 (PD-1) inhibitor, a widely used $\mathrm{ICl}$, were related to exosomal-transferred miR$34 a-5 p$ in cardiac senescence in a mouse model. Methods and results The upregulation of miR-34a-5p in cardiomyocytes induced by exosomes derived from PD-1 inhibitor-treated macrophages, accompanied by cardiac senescence, caused cardiac injury in mouse hearts. miR-34a-5p was identified as an exosomal transfer RNA to induce cardiac senescence-related injury. Inhibiting miR-34a-5p in macrophages attenuated the exosome $\mathrm{PD}^{\mathrm{PD}}$ inhibitor-induced pro-senescent effect in cardiomyocytes. TargetScan and luciferase assay showed that miR-34a$5 p$ targeted the serine/threonine-protein phosphatase 1 regulatory subunit 10 (PNUTS) 3'-untranslated region. Conclusions Exosomes derived from PD-1 inhibitortreated macrophages exerted a pro-senescent effect by modulating the miR-34a-5p/PNUTS signaling pathway. The findings might supply new targets to ameliorate cardiac injury in patients with cancer receiving PD-1 inhibitor treatment.

\section{INTRODUCTION}

Immune checkpoint inhibitors (ICIs) stand out as a significant advancement in the treatment of patients with cancer. ${ }^{1}$ These therapies are approved for a large variety of cancers in metastatic and late stages, and more recently in the adjuvant setting. ${ }^{2}$ They work by modulating immune-related cells. ${ }^{3}$ During approval, the activation of the immune system resulted in immune-related adverse effects (irAEs). ${ }^{4}$ Cardiac adverse events are likely one of the most uncommon irAEs, but with high fatality. ${ }^{5}$ The reporting of ICI-related cardiac adverse events has increased. ${ }^{6}$ However, the understanding of ICI-related cardiac adverse events is limited and needs to be improved as ICIs are being tested broadly in additional adjuvant settings and in combination with targeted and traditional cytotoxic therapies. ${ }^{1}$

Aging is the major risk factor for the decline in cardiovascular physiological functions and the development of cardiovascular diseases. ${ }^{7}$ Scientists have realized in the last few decades that the immune system contributes to cardiac senescence. ${ }^{8}$ Immune cells infiltrate the heart at gestation and remain in the myocardium, where they participate in essential functions throughout life. ${ }^{9}$ Under some circumstances, immune cells can cause irreversible damage, contributing to age-related heart failure. ${ }^{10}$ Among different kinds of immune cells, macrophages stand out for multiple mechanisms modulating the senescence process. ${ }^{11}$ Resident macrophages are also joined by recruited cells, which are produced in greater numbers during the senescence process and development of heart failure. ${ }^{12}$ A previous study revealed that macrophage infiltration in the myocardium is typically observed in ICI-associated cardiac injury. ${ }^{13}$ This study aimed to explore whether cardiac macrophage-induced cardiac senescence takes effect in the ICI-related cardiac injury.

Exosomes are cell-derived vesicles, which contain proteins, lipids, growth factors, microRNAs (miRNAs), and proinflammatory 
cytokines released through exocytosis. ${ }^{14}$ The recent literature suggests that condition-modified exosomes induce cardiac injury. ${ }^{15}$ Macrophage-derived exosomes in patients with diabetes showed proinflammation function, leading to cardiac fibrosis. ${ }^{16}$ Meanwhile, exosomes derived from modified macrophages showed a pro-DNA damaging effect, thus leading to senescence. ${ }^{17}$ However, whether macrophage-derived exosomes also play a role in cardiac senescence in the ICI-induced cardiotoxicity remains to be established.

The transcription of the miR-34 family of microRNAs is activated in cardiac injury. ${ }^{18}$ In cell-based studies, miR$34 \mathrm{a}$ is found to promote cardiac senescence. ${ }^{19}$ Extracellular vehicles (EVs) can transfer microRNA between cells. ${ }^{20}$ Recent findings have also suggested that EVs and microRNAs are involved in the communication between macrophages and resident cells, causing resident cell damage. ${ }^{21}$ Therefore, this study investigated the role of miR-34a-5p, macrophages, and PD-1 inhibitor, and explored whether exosomes could indeed transfer miR$34 a-5 p$ from macrophages to resident cardiomyocytes, thus causing cardiac cellular senescence.

\section{MATERIALS AND METHODS Animals}

Eight-week-old male $\mathrm{C} 57 / \mathrm{Bl6}$ mice were maintained in accordance with the guidelines published by the US National Institutes of Health (NIH). This study was conducted in compliance with the Guide for the Care and Use of Laboratory Animals published by the National Academy Press (NIH, revised in 1996). During the animal experiment, the investigator was blinded to the group allocation.

\section{Treatment using a PD-1 inhibitor in vivo}

Eight-week-old male $\mathrm{C} 57 / \mathrm{Bl} 6$ mice were treated with an InVivoPlus anti-mouse PD-1 inhibitor (Bioxcell, West Lebanon, USA), at a concentration of $5 \mathrm{mg} / \mathrm{kg}$, intraperitoneally, on days 1 and 14 (cycle: 28 days). After the experiments, mice were sacrificed by $\mathrm{CO}_{2}$ inhalation.

\section{Echocardiographic evaluation}

For echocardiography, 28 days after the first treatment of PD-1 inhibitor, mice were anesthetized with $1.5 \%-2 \%$ isoflurane and kept warm on a heated platform. During echo process, the vital signs were monitored. Vevo 2100 was applied to observe the echocardiographic parameters in mice to assess the cardiac functions (Vevo 2100, Visual Sonics, Canada). Short axis was applied to measure left ventricular internal diameter; diastole (LVID;d), left ventricular internal diameter; systole (LVID;s), left ventricular end-diastolic volume (LVEDV), left ventricular end-systolic volume (LVESV). The values of ejection fraction (EF) and fractional shortening (FS) were calculated.

\section{Quantitative reverse transcription-PCR (qRT-PCR)}

RNA was isolated using TRIzol reagent (Invitrogen, Carlsbad, USA), and cDNA was synthesized using an

\begin{tabular}{|c|c|}
\hline Genes & Sequences \\
\hline \multirow[t]{2}{*}{ p16 } & F: 5'-TTG GCC CAA GAG CGG GGA CA-3' \\
\hline & R: 5'-GCG GGC TGA GGC CGG ATT TA-3' \\
\hline \multirow[t]{2}{*}{ p21 } & F: 5'-TCCACAGCGATATCCAGACA-3' \\
\hline & R: 5'-GGACATCACAGGATTGGAC-3' \\
\hline \multirow[t]{2}{*}{ PNUTS } & F: 5'-AGGTACTATCGCCGACTGCT-3' \\
\hline & R: 5'-GGGCGGTCCGTGTCCATGGG-3' \\
\hline \multirow[t]{2}{*}{$\operatorname{miR}-34 a-5 p$} & F: 5'-GGCCAGCTGTGAGTGTTTCTITGG-3' \\
\hline & R: 5'-CTCGCTTCATCTTCCCTCTTGGG-3' \\
\hline \multirow[t]{2}{*}{ telomere length } & F: 5'-TGA AAG TAG AGG ATT GCC ACT G-3' \\
\hline & R: 5'-AGC CAG AAC AGG AAC GTA GC-3' \\
\hline \multirow[t]{2}{*}{ GAPDH } & F: 5'-GGA GCC AAA AGG GTC ATC AT-3' \\
\hline & R: 5'-GTG ATG GCA TGG ACT GTG GT-3' \\
\hline \multirow[t]{2}{*}{ U6 } & F: 5'-CTCGCTTCGGCAGCACA-3' \\
\hline & R: 5'-AACGCTTCACGAATTTGCGT-3' \\
\hline
\end{tabular}

Improm II reverse transcription kit (Promega, Wisconsin, USA). qRT-PCR was performed with SYBR Green to detect mRNA levels. The mRNA levels were calculated relative to the control Gapdh (for mRNA) or U6 (for miRNA) using the $2^{-\Delta \Delta \mathrm{Cq}}$ method. The primers for target genes are listed in table 1 .

\section{Immunofluorescence staining}

Deparaffinized tissue sections were stained with antibodies for sarcomeric- $\alpha$-actin (SAA; 1:30, Abcam, ab9465). Thereafter, the $\mathrm{p} 16^{\mathrm{INK} 4 \mathrm{a}}$ was used to detect cellular senescence (1:50; Abcam, ab211542). Blocked using 10\% goat serum, the sections were incubated with the antibody overnight at $4^{\circ} \mathrm{C}$. Following primary incubation, the slides were incubated with Alexa Fluor 488 (1:50; Invitrogen, Cat No A32731) or Alexa Fluor 594 (1:50; Invitrogen, Cat No A32744) for 1 hour at room temperature. The sections were counterstained with 4,6-diamino-2-phenyl indole (DAPI). Fluorescence was detected under a microscope.

\section{Cardiomyocyte isolation and culture}

Mouse ventricular myocytes were isolated from C57BL/6 mice. The animals were euthanized by cervical dislocation. A digestion solution containing $0.25 \%$ trypsin and collagenase I was applied to digest heart. After 3 hours of differential sedimentation and adhesion, the myocytes were separated. They were then cultured in low-glucose Dulbecco's modified Eagle's medium containing 10\% fetal bovine serum (FBS).

\section{Senescence-associated $\beta$-galactosidase assay}

The senescence-associated $\beta$-galactosidase (SA- $\beta$-gal) assay (Cell Signaling Technology, Massachusetts, USA) was applied to assess cellular senescence. Briefly, the cells at the density of $2 \times 10^{4}$ were fixed with $2 \%$ paraformaldehyde and incubated with SA- $\beta$-gal staining solution as previously reported. ${ }^{22}$ 


\section{Western blot analysis}

Western blot analysis was conducted as previously described. ${ }^{23}$ Primary antibodies, including Flotillin-1 (ab41927), Tsg101 (ab125011), CD63 (ab217345), p21 (ab188224), p16 ${ }^{\text {INK4a }}$ (ab211542), and $\beta$-actin (ab179467) were purchased from Abcam. PNUTS (14171) was purchased from Cell Signaling Technology.

\section{Antagomir studies}

Chemically modified antisense oligonucleotides were designed to target miR-34a-5p. Eight-week-old C57/B16 mice were subjected to sham or PD-1 inhibitor treatment. Then, the mice were injected (intraperitoneally) with antagomir-34a-5p $(80 \mathrm{mg} / \mathrm{kg})$ or control antagomir $(80 \mathrm{mg} / \mathrm{kg})$ for three consecutive days as previously reported. ${ }^{24}$

\section{Cell culture and cell treatment}

HL-1 murine cardiomyocytes were maintained in fibronectin-coated flasks, supplemented with $10 \%$ FBS, $100 \mathrm{U} / \mathrm{mL}$ penicillin, $100 \mathrm{mg} / \mathrm{mL}$ streptomycin, and $2 \mathrm{mM}$ L-glutamine. The cell culture was exposed to $5 \mu \mathrm{g} /$ $\mathrm{mL}$ of the treatment solution for short durations. ${ }^{25}$

\section{Cell proliferation assay}

The rate of cell proliferation was assessed using the cell counting kit-8 (CCK-8) assay, performed following the manufacturer's protocol. Briefly, the cells grown in a 96-well plate were incubated with the CCK-8 solution for 1 hour at $37^{\circ} \mathrm{C}$, and the absorbance of each well at $450 \mathrm{~nm}$ was recorded.

\section{Cell cycle assay}

Cold anhydrous ethanol (70\%) fixed cells were treated with propidium iodide (PI) (Sigma, St. Louis, Missouri, USA) and RNase A. A flow cytometer equipped with Cell Quest software was used to detect the cell cycle distribution.

\section{Flow cytometric analysis of cell apoptosis}

Cellular apoptosis was detected using an Annexin V fluorescein isothiocyanate (FITC) and PI kit. Briefly, washed cells were resuspended in Annexin $\mathrm{V}$ binding buffer, then stained with Annexin V and PI at room temperature and then analyzed by bivariate flow cytometry using a BD FACS Canto II equipped with BD FACSDiva Software (Becton-Dickinson, San Jose, California, USA).

\section{Isolation of cardiac macrophages}

Cardiac macrophages were isolated as previously described. ${ }^{26}$ Briefly, the excised hearts were washed with warmed Hanks' balanced salt solution. Then the hearts were placed in warm digestion buffer containing Liberase TH ( $5 \mathrm{mg} / \mathrm{mL}$, Roche) and DNase1 (2000 units, Sigma) for $5 \mathrm{~min}$, triturated with a pipette, and passed through a $40 \mu \mathrm{m}$ filter. To isolate macrophages, the centrifuged cells were incubated with $50 \mu \mathrm{L}$ of anti-CD 45 magnetic beads for $30 \mathrm{~min}$. The cells were then allowed to flow through the MACS magnetic column with a magnet in place.

\section{Isolation and characterization of exosomes}

The exosomes were isolated and purified from the supernatants of normal macrophages and $5 \mu \mathrm{g} / \mathrm{mL}$ PD-1 inhibitor-treated macrophages. Briefly, the supernatants were collected after 48 hours culture. The exosome quick extraction solution was added to the filtered solution at a $1: 5$ ratio and stored at $4^{\circ} \mathrm{C}$ for at least 12 hours.

The morphology of exosomes was observed by transmission electron microscopy (TEM, JEM-1400plus). The size and concentration were determined by nanoparticle tracking analysis (NTA). Western blot analysis was used for detecting exosomal markers Flotillin-1, Tsg101, and CD63. At meanwhile, $\beta$-actin in the whole-cell lysate was used as control.

\section{miR-34a-5p inhibition in vitro}

Macrophages were seeded into six-well plates at a density of $1 \times 10^{5}$ cells per well. To induce the inhibition of miR-34a-5p, the cells were transfected with an miR$34 a-5 p$ inhibitor or a negative control (NC) inhibitor (pre-miR miRNA Precursors, Life Technologies, Karlsruhe, Germany) using X-treme transfection reagent (Roche Applied Science, Penzberg, Germany). The cells were harvested for further analysis 48 hours after transfection, and qRT-PCR was applied to quantify the transfection efficiency.

\section{Relative telomere length measurement}

Relative telomere length quantification in cardiomyocytes was performed using the PCR approach based on a previously established method, ${ }^{27}$ using Gapdh as the normalizing gene. The primer pairs used to detect the telomere length are listed in table 1.

\section{Relative telomerase activity measurement}

The telomerase activity of cardiomyocytes was examined using a Telo TAGGG Telomerase PCR ELISA Plus kit according to the manufacturer's protocols as described previously. ${ }^{28}$

\section{Luciferase reporter assay}

The 3'-UTRs of PNUTS were synthesized, annealed, and inserted into the SacI and HindIII sites of the pmiR-reporter luciferase vector (Ambion), downstream of the luciferase stop codon to induce the mutagenesis of PNUTS. The cardiomyocytes were seeded into a 24-well plate for luciferase assay. After overnight culture, the cells were co-transfected with a wild-type (WT) or mutated plasmid and equal amounts of miR34a-5p mimic or miR-NC mimic. Luciferase assays were performed using a dual-luciferase reporter assay system (Promega) 24 hours after transfection.

\section{Transient transfection}

For the overexpression of PNUTS, the cardiomyocytes were transduced with adenoviral PNUTS (Ad-PNUTS) or adenoviral control (Ad-Ctrl) as described 
previously. ${ }^{29}$ The transfection efficiency was confirmed by qRT-PCR and western blot analysis.

\section{Statistical analysis}

Data were expressed as mean \pm SD. Statistical significance of differences among groups was tested by oneway analysis of variance (ANOVA) or repeated measures ANOVA. Comparisons between two groups were done using Student's t-test or paired t-test. A value of $p<0.05$ was considered statistically significant.

\section{RESULTS}

PD-1 inhibitor-induced cardiac injury increased with heart senescence

Whether a PD-1 inhibitor impaired heart function by increasing heart senescence was investigated in a murine model. Echocardiography showed a significant decrease in left ventricular EF and FS in the PD-1 inhibitor group compared with the sham group (figure 1A-C). However, neither the ratio of heart weight to body weight nor the
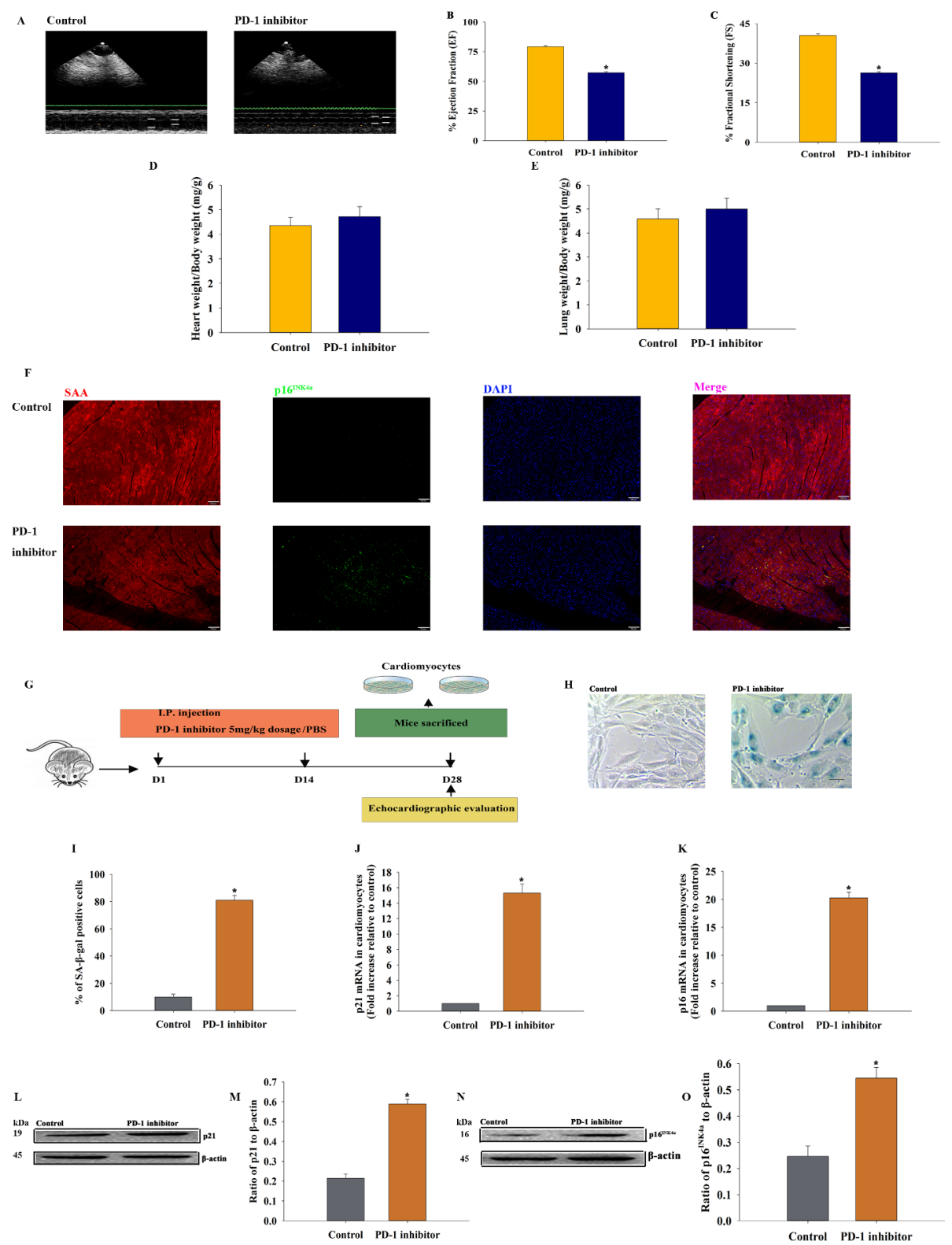

Figure 1 PD-1 inhibitor-induced cardiac injury increased with heart senescence. (A) Representative images of echocardiography exhibiting changes in cardiac function in each group. Echocardiographic analysis of ejection fraction (EF) (B) and fractional shortening (FS) (C) in week 4 after the first cycle of PD-1 inhibitor treatment or control operation. (D) Ratio of heart weight to body weight. (E) Ratio of lung weight to body weight. $(\mathrm{F})$ Immunofluorescence detected p16 ${ }^{\text {INK4a }}$ (green) and SAA (red) double-positive cells located in mouse hearts. Scale bar: $100 \mu \mathrm{m}$. (G) Cardiomyocytes were isolated from control and PD-1 inhibitor-treated mice. (H) Representative images of senescence-associated $\beta$-galactosidase (SA- $\beta$-gal) staining. Scale bar: $20 \mu \mathrm{m}$. (I) Percentage of $\beta$-gal-positive cells. $(\mathrm{J}, \mathrm{K}) \mathrm{p} 21$ and p16 mRNA levels were analyzed using quantitative reverse transcription-PCR. $(L-O) p 21$ and p16 protein levels were analyzed using western blot analysis. " $p<0.05$ vs control in Student's t-test, $n=6$. DAPI, 4,6-diamino-2-phenyl indole; PD-1, programmed cell death 1. 
lung weight to body weight showed significant difference between control and PD-1 inhibitor treatment group (figure 1D,E).

Immunostaining was conducted to verify whether organ senescence involved cellular senescence of all cell types or a specific cell type. More p $16^{\mathrm{INK} 4 \mathrm{a}}$-positive cells were located on cardiomyocytes, which were also positive for cardiomyocyte marker SAA in the PD-1 inhibitor-treated mice (figure 1F). Cardiomyocytes were isolated from control and PD-1 inhibitor-treated mice (figure 1G). SA- $\beta$-gal staining revealed more positive cells in PD-1 inhibitor-treated mouse hearts compared with control mouse hearts (figure 1H,I). qRT-PCR and Western blot analysis confirmed increased expression levels of senescence-related genes $p 21$ and $p 16$ in PD-1 inhibitor-treated cardiomyocytes compared with controls (figure $1 \mathrm{~J}-\mathrm{O}$ ).

\section{miR-34a-5p dynamically modulated PD-1 inhibitor-related} cardiac senescence

Cardiomyocytes were isolated for the characterization of senescence (figure 2A). Microarray analysis was performed between cardiomyocytes isolated from the control mice and PD-1 inhibitor-treated mice (figure 2B). As shown in figure 2B, miR-34a-5p in heart treated with a PD-1 inhibitor was probably responsible for cardiac injury and cardiac senescence. QRT-PCR further confirmed that miR-34a-5p was more abundant in cardiomyocytes and macrophages isolated from PD-1 inhibitor-treated mouse hearts (figure 2C,D). Meanwhile, miR-34a-5p mRNA levels in the heart tissue from PD-1 inhibitortreated mice increased in a time-dependent manner (figure 2E). MiR-34a-5p inhibitor transfection was performed in vivo to evaluate whether miR-34a-5p inhibition treatment influenced PD-1 inhibitor-modulated
$\mathbf{A}$

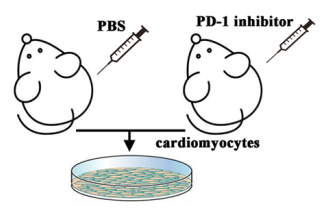

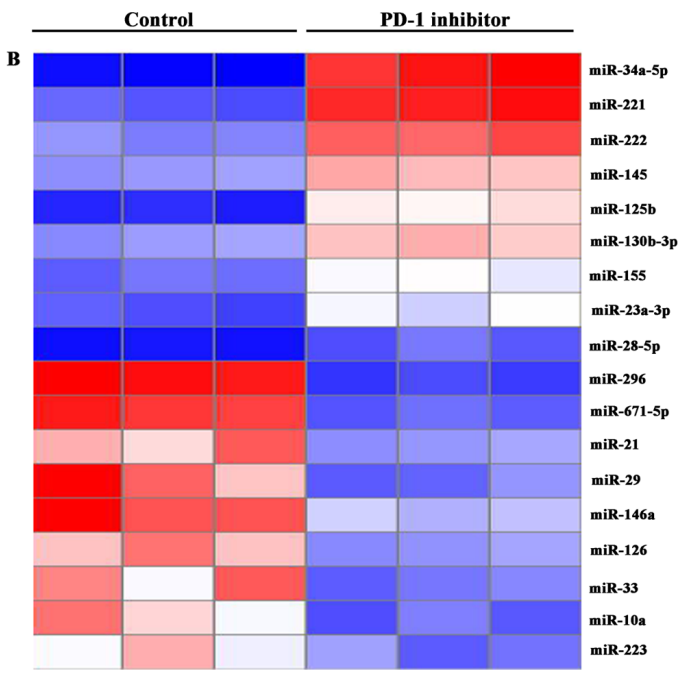

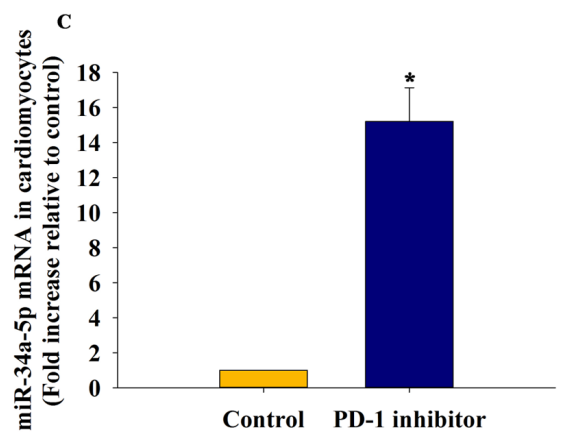

D

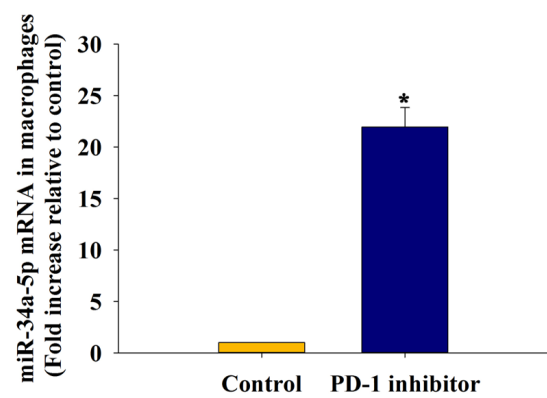

$\mathbf{E}$



Control PD-1 inhibitor

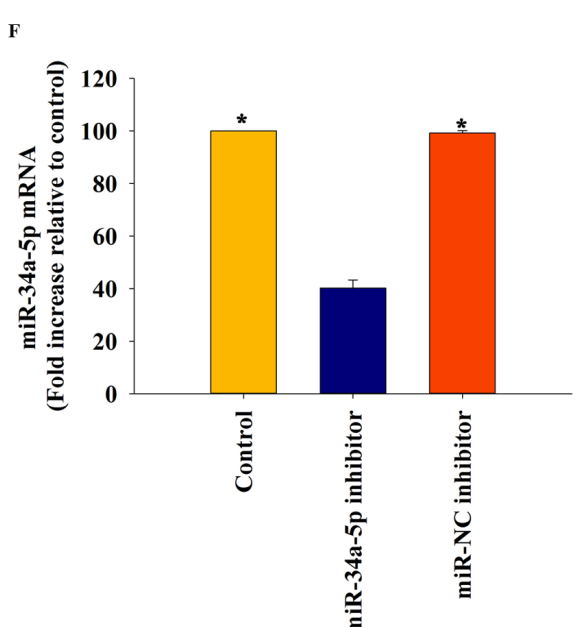

Figure 2 miR-34a-5p was profoundly induced by a PD-1 inhibitor. (A) Cardiomyocytes were isolated from control and PD-1 inhibitor-treated mice. (B) Heat map of microRNAs (miRs) differentially expressed between cardiomyocytes isolated from PD-1 inhibitor-treated mice and control mice. (C-E) MiR-34a-5p expression was validated using quantitative reverse transcriptionPCR (qRT-PCR) in isolated cardiomyocytes, macrophages and cardiac tissues from PD-1 inhibitor-treated mice and control mice. ${ }^{*} p<0.05$ vs control in Student's t-test, $n=6$. Mouse hearts were locally transfected with an inhibitor control (miR-NC inhibitor) or miR-34a-5p inhibitor. Untreated mice were used as control. (F) Transfection efficiency was analyzed using qRT-PCR. $\mathrm{p}<0.05$ vs miR-34a-5p inhibitor in one-way analysis of variance, $\mathrm{n}=6$. NC, negative control; PD-1, programmed cell death 1 . 
A

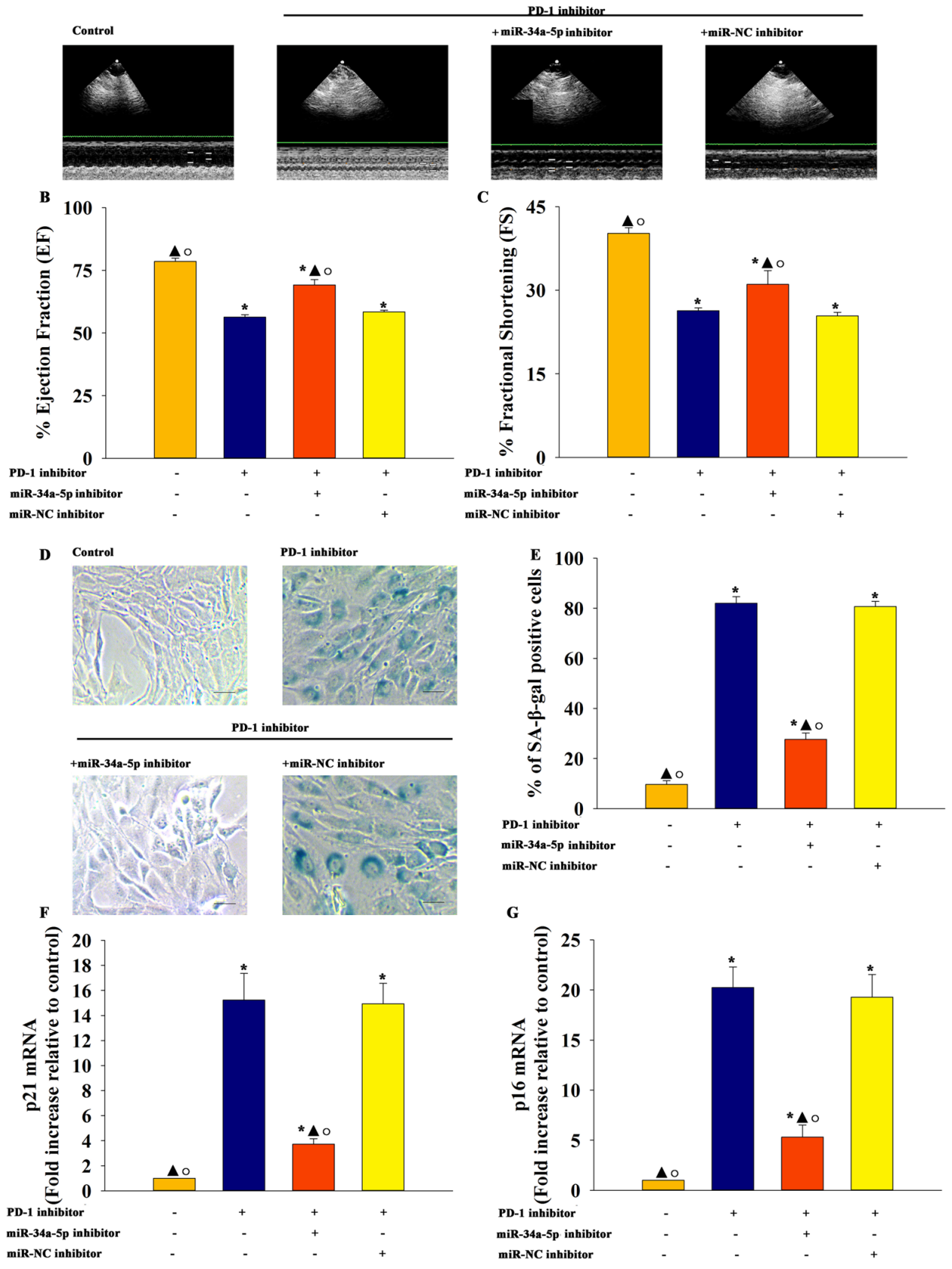

Figure 3 miR-34a-5p dynamically modulated PD-1 inhibitor-related cardiac senescence. Mouse hearts were locally transfected with miR-NC inhibitor or miR-34a-5p inhibitor. The mice were treated with a PD-1 inhibitor. Untreated mice were used as control. (A) Representative images of echocardiography exhibiting changes in cardiac function in each group. Echocardiographic analysis of EF (B) and FS (C) in week 4 after treatment. (D) Representative images of senescence-associated $\beta$-galactosidase (SA- $\beta$-gal) staining. Scale bar: $20 \mu \mathrm{m}$. (E) Percentage of $\beta$-galactosidase $(\beta$-gal)-positive cells. (F, G) p21 and p16 mRNA levels were analyzed using quantitative reverse transcription-PCR. ${ }^{*} p<0.05$ vs control; ${ }^{\wedge} p<0.05$ vs PD-1 inhibitor; $\mathrm{p}<0.05$ vs PD-1 inhibitor+miR NC inhibitor in one-way analysis of variance, $n=6$. miR, NC, negative control; microRNA; PD-1, programmed cell death 1

cardiac senescence and cardiac function (figure $2 \mathrm{~F}$ ). Echocardiography data revealed that PD-1 inhibitortreated mice had significant impairment in cardiac function compared with control mice. However, mice treated with PD-1 inhibitor+miR-34a-5p inhibitor showed recovery in cardiac function (figure $3 \mathrm{~A}-\mathrm{C}$ ). Meanwhile, more SA- $\beta$-gal-positive cardiomyocytes were found in PD-1 inhibitor-treated mice compared with control mice.
However, the miR-34a-5p inhibitor impaired the increase in positive cells (figure $3 \mathrm{D}, \mathrm{E}$ ). As shown in figure $3 \mathrm{~F}, \mathrm{G}$, the expression levels of senescence-related genes $p 21$ and p16 increased in PD-1 inhibitor-treated mouse cardiomyocytes compared with control mouse cardiomyocytes. However, the expression of senescence-related genes $p 21$ and $p 16$ decreased in the PD-1 inhibitor+miR-34a-5p inhibitor group compared with the PD-1 inhibitor group, 
but no change was observed in the PD-1 inhibitor+miR NC inhibitor group.

\section{Cardiomyocyte senescence and apoptosis did not occur when a PD-1 inhibitor was added in vitro}

The proliferation under PD-1 treatment was first examined to investigate the potential pro-senescence effects of a PD-1 inhibitor on cardiomyocytes. No hampering in proliferation was observed when HL-1 cardiomyocytes were exposed to a PD-1 inhibitor (online supplemental figure S1A). Meanwhile, the administration of the PD-1 inhibitor did not affect the cell cycle (online supplemental figure S1B,C). The PD-1 inhibitor did not induce SA- $\beta$-gal-positive cells (online supplemental figure SD,E). These results indicated that the PD-1 inhibitor only did not affect the biological activity of cardiomyocytes, thus leading to cellular senescence. Also, the PD-1 inhibitor did not induce cellular apoptosis (online supplemental figure S1F,G). Similarly, we found that miR-34a-5p expression was slightly increased in PD-1 inhibitor-treated cardiomyocytes, however, with no significant difference (online supplemental figure $\mathrm{S} 1 \mathrm{H}$ ).

\section{Macrophage-derived exosomes pretreated with a PD-1 inhibitor provoked cardiomyocyte senescence}

Given the conditioned exosomes isolated from macrophages had a pro-senescent effect, whether exosomes derived from PD-1 inhibitor-pretreated macrophages affected cardiomyocyte senescence was determined. TEM and NTA showed that exosomes isolated from macrophages exhibited a round morphology and size of 50-100 nm. Moreover, the expression of exosome markers Flotillin-1, Tsg101, and CD63 was confirmed by western blot analysis (figure 4A-C). Also, the effects of PD-1 inhibitor-conditioned exosomes on cardiomyocyte senescence was determined. Exosome derived from PD-1 inhibitor-treated macrophages $\left(\right.$ exosome $^{\mathrm{PD}-1 \text { inhibitor }}$ ) induced cardiomyocyte senescence, showing that more cells were trapped in the G0/G1 phase as measured using flow cytometric analysis cell scan (FACS) (figure 4D,E), with the increased expression levels of cellular senescence-related genes $p 21$ (figure 4F) and p16 (figure 4G), decreased telomere length (figure $4 \mathrm{H}$ ) and telomerase activity (figure $4 \mathrm{I}$ ), and a higher percentage of SA- $\beta$-gal-positive cells (figure 4J,K). However, exosomes from untreated macrophages showed no significant pro-senescent effect, indicating that the observed pro-senescent effects were PD-1 inhibitor-specific.

\section{miR-34a-5p transferred by exosomes caused cardiac senescence}

Exosomal RNA was extracted from three PD-1 inhibitortreated macrophages and three control macrophages, and the expression profile was analyzed using the miR array to identify exosomal miRs. As a result, the maximum difference was for miR-34a-5p, a cellular senescence-related miR, which was confirmed by qRT-PCR (figure 5A,B). Exosomes prepared from macrophages were labeled with DiI to confirm whether this miR could be transferred to cardiomyocytes through exosomes. Exosome uptake by cardiomyocytes was observed (figure 5C). Also, miR-34a-5p was detected in cardiomyocytes incubated with exosome $\mathrm{P}^{\mathrm{PD}-1}$ inhibitor compared with cardiomyocytes without any treatment. As expected, miR-34a-5p had the strongest upregulation in cardiomyocytes incubated with exosome $\mathrm{PD}^{\mathrm{PD}-1}$ inhibitor (figure 5D). Furthermore, the expression of miR-34a-5p in macrophages was silenced. The qRT-PCR results confirmed a significant decrease in the expression level of miR-34a-5p in macrophages even if treated with a PD-1 inhibitor (figure 5E). Macrophages were transfected with an miR-34a-5p inhibitor or an miR-NC inhibitor and were then subjected to a PD-1 inhibitor. Then, exosomes were collected. The qRT-PCR results revealed that the PD-1 inhibitor induced miR$34 a-5 p$ accumulation in the exosomes, which was abolished by antago-miR (figure $5 \mathrm{~F}$ ). Exosomes derived from macrophages, which were transfected with an miR-34a-5p inhibitor or an miR-NC inhibitor and then treated with a PD-1 inhibitor or treated only with a PD-1 inhibitor, were added to cardiomyocytes. In parallel experiments, cardiomyocytes without any treatment were used as control. Then, the expression of miR-34a-5p in cardiomyocytes was examined using qRT-PCR. The results revealed that exosome $\mathrm{P}^{\mathrm{PD}-1}$ inhibitor transferred miR-34a-5p to cardiomyocytes, while this transfer was destroyed by endogenous miR-34a-5p inhibition in macrophages (figure 5G).

Subsequently, exosomes derived from macrophages, which were transfected with miR-34a-5p inhibitor or an miR-NC inhibitor and then treated with a PD-1 inhibitor or treated only with a PD-1 inhibitor, were added to cardiomyocytes. Exosome $\mathrm{PD}^{\mathrm{PD}-1 \text { inhibitor }}$ induced cardiac senescence, while miR-34a-5p inhibition in macrophages significantly reduced the percentage of G0/G1-phase cells (figure $6 \mathrm{~A}$ ), the number of SA- $\beta$-gal-positive cells (figure 6B,C), and the expression of classical senescenceassociated genes (figure 6D,E), while recovered the telomere length and telomerase activity (figure 6F,G). These results strongly supported that macrophage-derived exosomes with a PD-1 inhibitor exerted a pro-senescent effect partially through direct miR-34a-5p transfer.

\section{Exosomal miR-34a-5p sponged PNUTS to induce cardiac senescence}

To identify the target genes of miR-34a-5p regulation, the bioinformatics database was used to speculate a putative binding site between miR-34a-5p and PNUTS (online supplemental figure S2A), which was confirmed by the dual-luciferase gene reporter assay. The relative luciferase activity was significantly weakened in the WT PNUTS+miR-34a-5p mimic group (online supplemental figure S2B). The cardiomyocytes were treated with exosome $^{\mathrm{PD}-1 \text { inhibitor }}$ to investigate the regulatory effect of exosomal-delivered miR-34a-5p on PNUTS expression in cardiomyocytes; the untreated cardiomyocytes were used as control. As expected, exosome $\mathrm{eD}^{\mathrm{PD}-1}$ inhibitor markedly inhibited PNUTS expression in cardiomyocytes, while 
A
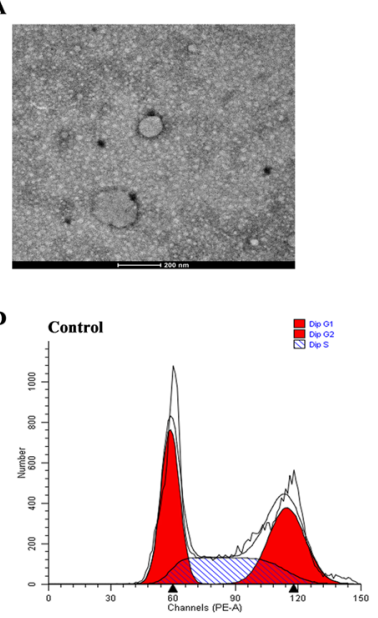

E
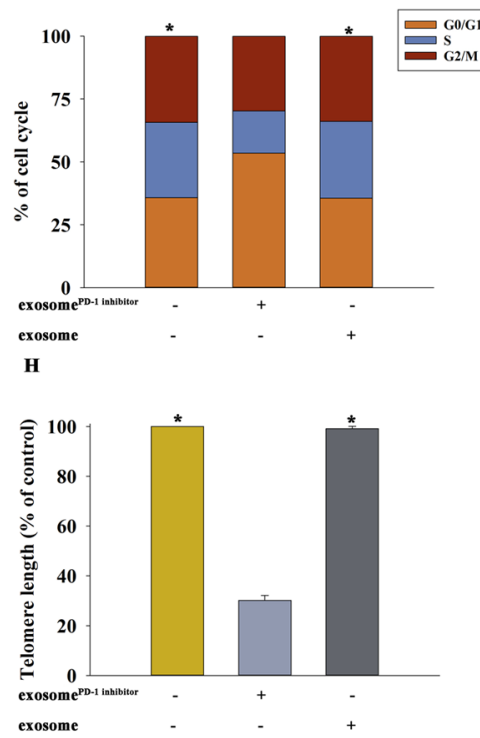

K Control
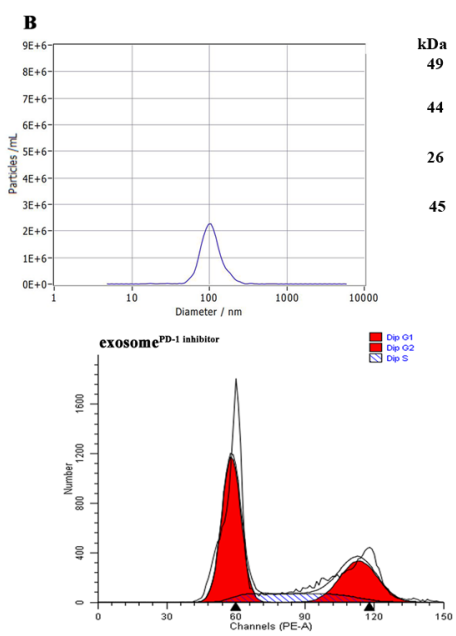

F

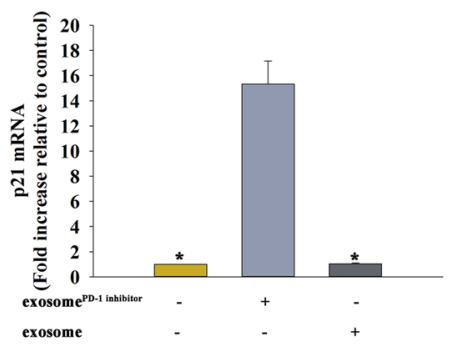

$$
\text { I }
$$

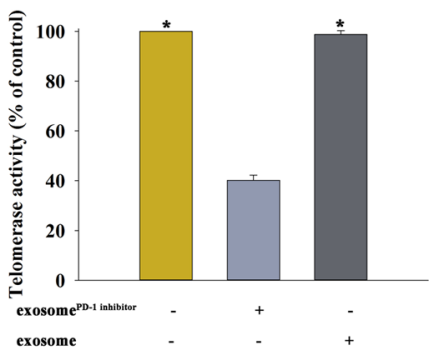

exosome
exosome

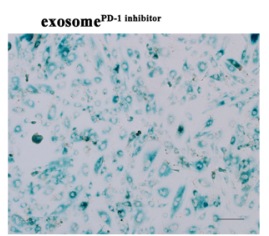

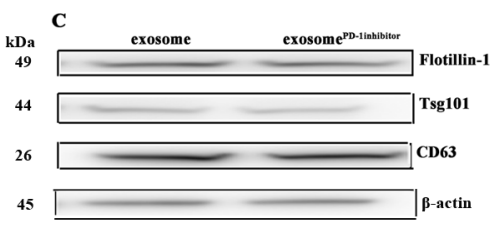

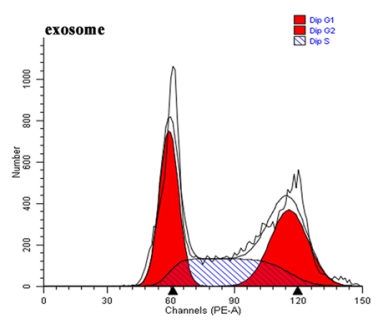

G
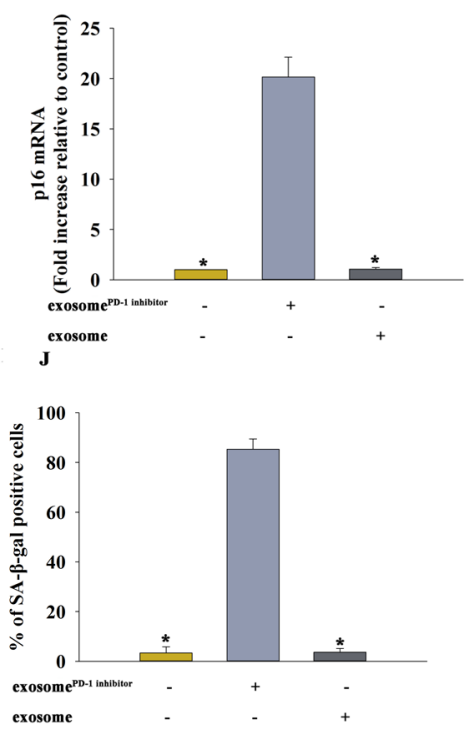

exosome



Figure 4 Macrophage-derived exosomes pretreated with a PD-1 inhibitor provoked cardiomyocyte senescence. Confirmation of exosomal collection using transmission electron microscopy (TEM), nanoparticle tracking analysis (NTA), and western blot analysis. (A) Representative TEM image. (B) Size range of exosomes checked using NTA analysis. (C) Representative western blot images showing that the exosomal marker Flotillin-1, Tsg101, and CD63 were expressed in exosome and exosome ${ }^{\mathrm{PD}-1}$ inhibitor. $\beta$-Actin in macrophages lysate was examined as control. (D, E) Cell cycle distribution was analyzed. ${ }^{*} p<0.05$ vs exosome ${ }^{P D-1}$ inhibitor in $\chi^{2}$ analysis, $n=6$. $(F-H)$ Quantitative reverse transcription-PCR analyzed $p 21, p 16$, and telomere length mRNA levels. (I) Relative telomerase activity was measured. (J) Percentage of $\beta$-galactosidase ( $\beta$-gal)-positive cells. (K) Representative images of senescence-associated $\beta$-galactosidase (SA- $\beta$-gal) staining. Scale bar: $50 \mu \mathrm{m}$. ${ }^{*} \mathrm{p}<0.05$ vs exosome ${ }^{\mathrm{PD}-1}$ inhibitor in repeated measures analysis of variance, $n=6$. PD-1, programmed cell death 1

the inhibition of miR-34a-5p in macrophages rescued the expression of PNUTS (online supplemental figure S2C,D). These data suggested that PNUTS were genuine targets of miR-34a-5p in cardiomyocytes.

Ad-PNUTS transfection enforced PNUTS overexpression in cardiomyocytes to explore the role of PNUTS in exosome $\mathrm{P}^{\mathrm{PD}-1}$ inhibitor -induced senescence, which was confirmed by qRT-PCR (figure 7A) and western blot analysis (figure 7B,C). Cardiomyocytes were transfected with Ad- PNUTS or Ad-Ctrl as control, and treated with exosome ${ }^{\mathrm{PD}-1}$ inhibitor. In parallel, cardiomyocytes were treated with exosome $\mathrm{PD}^{\mathrm{PD}-1}$ inhibitor . The untreated cardiomyocytes were used as control. PNUTS overexpression restrained the pro-senescent effects of exosome ${ }^{\mathrm{PD}-1}$ inhibitor, decreasing the percentage of $\mathrm{G} 0 / \mathrm{G} 1$-phase cells (figure 7D), the number of SA- $\beta$-gal-positive cells 


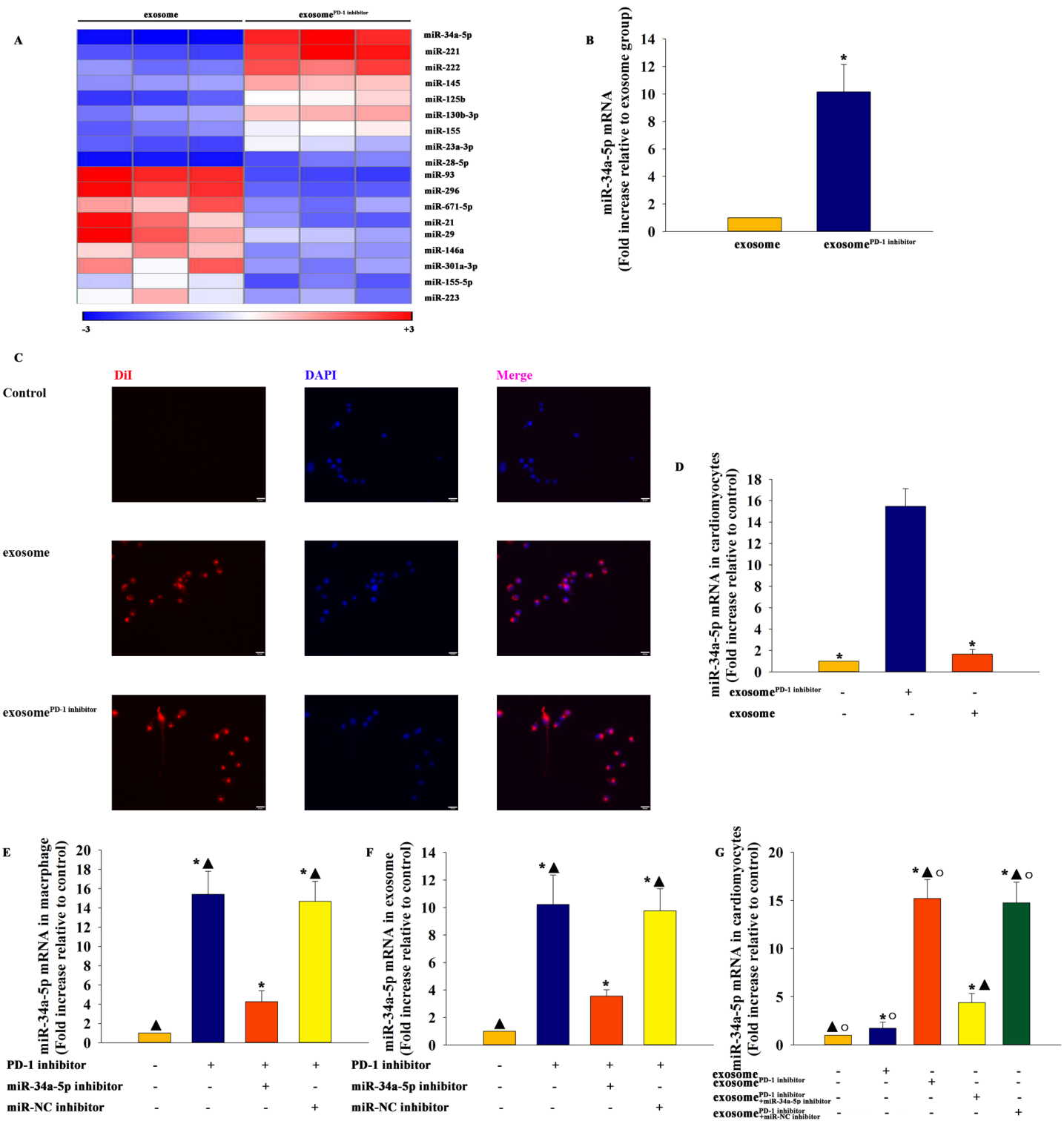

Figure 5 miR-34a-5p transferred by macrophage-derived exosomes to cardiomyocytes. (A) Heat map of the microRNAs (miRs) differentially expressed between macrophage-derived exosomes pretreated with a PD-1 inhibitor (exosome ${ }^{\mathrm{PD}-1 \text { inhibitor) }}$ and macrophage-derived exosomes without any treatment (exosome). (B) Relative miR-34a-5p expression was validated using quantitative reverse transcription-PCR (qRT-PCR) in exosome ${ }^{\mathrm{PD}-1 \text { inhibitor }}$ and exosome; ${ }^{*} \mathrm{p}<0.05$ vs exosome in paired ttest, $n=3$; (C) Dil-labeled macrophages are shown. Scale bar: $20 \mu \mathrm{m}$. (D) MiR-34a-5p mRNA was examined using qRT-PCR in cardiomyocytes incubated with exosome $\mathrm{e}^{\mathrm{PD}-1 \text { inhibitor }}$ or exosome. Cardiomyocytes without any treatment were used as control; $\mathrm{p}<0.05$ vs exosome $\mathrm{PD}^{\mathrm{P} \text { inhibitor }}$ in repeated measures analysis of variance (ANOVA), $n=6$. (E) miR inhibitor-mediated transfection efficiency in macrophages was demonstrated using qRT-PCR. ${ }^{*} p<0.05$ vs control; ${ }^{\mathbf{A}} p<0.05$ vs PD-1 inhibitor+miR-34a-5p inhibitor in repeated measures ANOVA, $n=6$. (F) miR-34a-5p mRNA in exosomes was examined using qRT-PCR. $p<0.05$ vs control; ${ }^{\mathbf{\Delta}} p<0.05$ vs PD-1 inhibitor+miR-34a-5p inhibitor in repeated measures ANOVA, $n=6$. (G) miR-34a-5p mRNA in cardiomyocytes was examined using qRT-PCR. $p<0.05$ vs control; ${ }^{\mathbf{\Lambda}} p<0.05$ vs exosome; ${ }^{\circ} p<0.05$ vs exosome ${ }^{\mathrm{PD}-1}$ inhibitor+miR-34a-5p inhibitor in repeated measures ANOVA, $n=6$. PD-1, programmed cell death 1

(figure $7 \mathrm{E}, \mathrm{F}$ ), and the expression of classical senescenceassociated genes p21 and p16 (figure 7G,H). Meanwhile, it increased the telomere length and telomerase activity (figure 7I,J).

\section{DISCUSSION}

One of the most exciting developments in cancer treatment is immunotherapy, which activates the immune system of patients to attack malignancies. ${ }^{30}$ Among the immunotherapy armamentarium are ICIs, which have shown promising results. ${ }^{31}$ In parallel with the increased use, the recognition of irAEs has also improved. Recently, cardiac injury has gained the attention of researchers. ${ }^{23}$ The indications for their use in cancer treatment continue to expand for an increasing number of malignancies, and in some as first-line therapy. Thus, increased awareness is 




Figure 6 miR-34a-5p transferred by exosomes caused cardiac senescence. (A) Cell cycle distribution was analyzed, ${ }^{*} p<0.05$ vs control; ${ }^{\mathbf{A}} p<0.05$ vs exosome ${ }^{\mathrm{PD}-1}$ inhibitor+miR-34a-5p inhibitor in $\chi^{2}$ analysis, $n=6$. (B) Percentage of $\beta$-galactosidase ( $\beta$-gal)positive cells. (C) Representative images of senescence-associated $\beta$-galactosidase (SA- $\beta$-gal) staining. Scale bar: $50 \mu \mathrm{m}$. (D-F) Quantitative reverse transcription-PCR analyzed p21, p16, and telomere length mRNA levels. (G) Relative telomerase activity was measured. Each column represents the mean \pm SD of six independent experiments. ${ }^{*}<0.05$ vs control; ${ }^{\mathbf{\Delta}} p<0.05$ vs

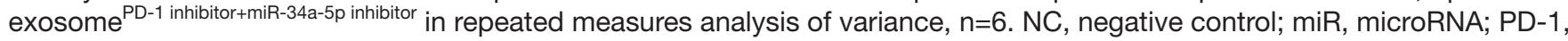
programmed cell death 1.

needed to explore the mechanism of ICI-related cardiac injury. Our research results revealed that the cardiac function decreased apparently in mice 4 weeks after the first treatment (two cycles) of PD-1 inhibitor, in terms of both systolic function and diastolic function, which was consistent with previous clinical findings. ${ }^{32}$

As an independent risk factor for cardiovascular diseases, cardiac senescence contributes to elevated cardiovascular morbidity and mortality. ${ }^{33}$ Senescence leads to increased cellular senescence in a number of tissues and is frequently associated with increased expression levels of the senescence biomarker, $\mathrm{p} 16^{\text {Ink4a }}$, impaired proliferation, and tissue regeneration. ${ }^{34}$ This study found that $\mathrm{p} 16^{\text {Ink4a }}$ was localized mainly in cardiomyocytes, indicating that cardiomyocytes were most susceptible to senescence during PD-1 inhibitor-induced cardiac senescence. 

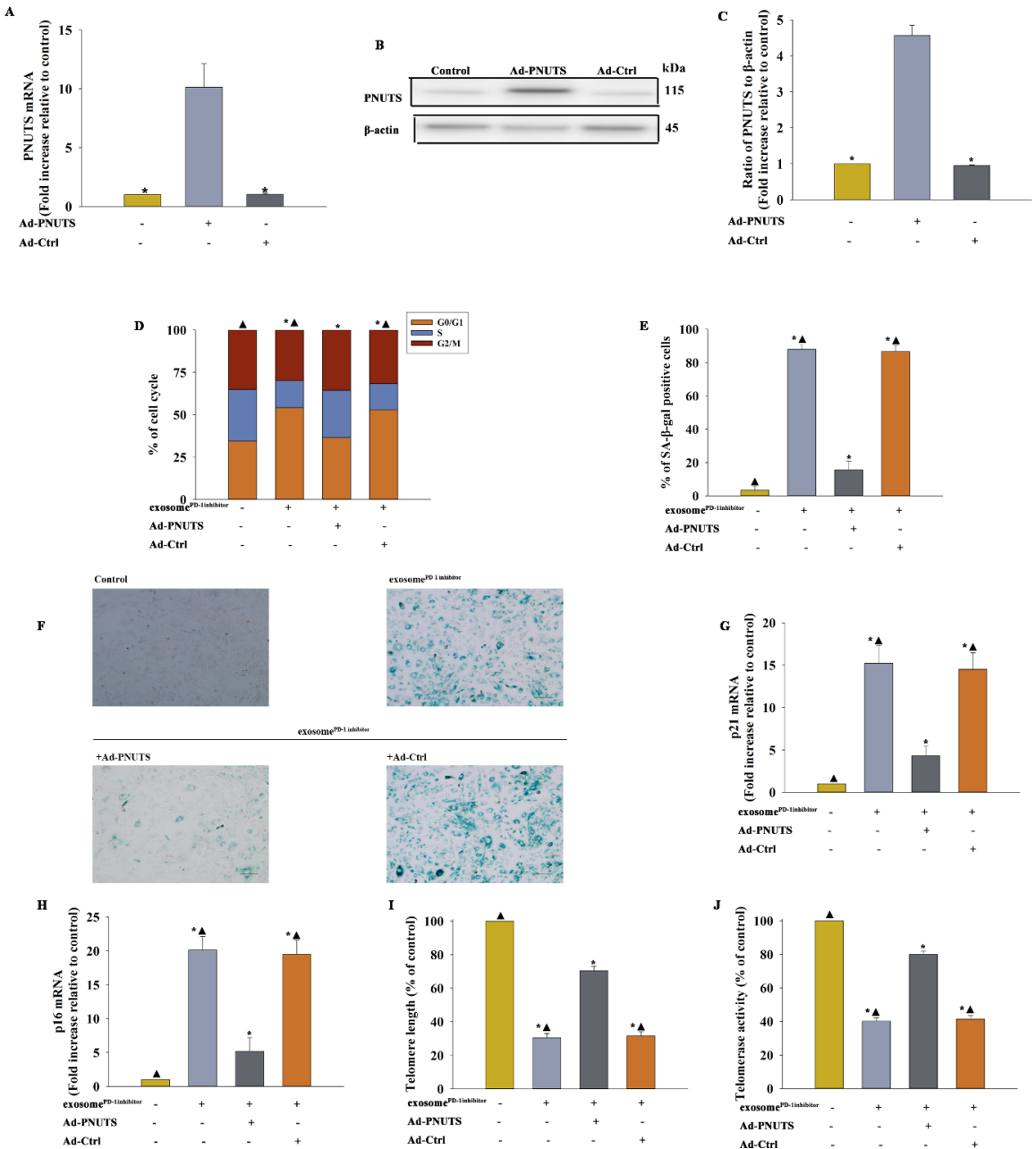

Figure 7 Exosomal miR-34a-5p sponged PNUTS to induce cardiac senescence. (A-C) Cardiomyocytes were transfected with Ad-PNUTS or Ad-Ctrl as control. Transfection efficiency was determined using quantitative reverse transcription-PCR (qRTPCR) (A) and Western blot analysis (B and C). ${ }^{*} \mathrm{p}<0.05$, vs Ad-PNUTS in repeated measures analysis of variance (ANOVA), $n=6$ (qRT-PCR), $n=3$ (western blot). (D) Cell cycle distribution was analyzed. ${ }^{*} p<0.05$ vs control; ${ }^{\wedge} p<0.05$ vs exosome ${ }^{\text {PD-1 inhibitor }}+{ }^{A}$ AdPNUTS in $\chi^{2}$ analysis, $n=6$. (E) Percentage of $\beta$-galactosidase ( $\beta$-gal)-positive cells. (F) Representative images of senescenceassociated $\beta$-galactosidase (SA- $\beta$-gal) staining. Scale bar: $50 \mu \mathrm{m}$. (G-I) qRT-PCR analyzed p21, p16, and telomere length mRNA levels. (J) Relative telomerase activity was measured. ${ }^{*} p<0.05$ vs control; ${ }^{\mathbf{A}} p<0.05$ vs exosome ${ }^{\mathrm{PD}-1 \text { inhibitor }}+$ Ad-PNUTS in repeated measures ANOVA, $n=6$.

In tumor cells, ICIs promoted telomere dysfunction and suppressed tumor progression by the activation of DNA damage checkpoints, which induced cell cycle arrest. ${ }^{35}$ The present study evaluated the effect of a PD-1 inhibitor on cardiac dysfunction and explored potential mechanisms. The results indicated that the PD-1 inhibitor induced cardiac dysfunction, accompanied by cell cycle arrest and telomere shortening.

Exosomes are vesicles of endocytic origin released by many cells. These vesicles can mediate communication between cells, facilitating processes such as proinflammation, pro-senescence, and miR transfer. ${ }^{36}$ Indeed, only PD-1 inhibitor treatment did not induce cellular senescence in cardiomyocytes in vitro. However, opposite effects were found in vivo. Hence, it was speculated that another kind of cells might take part in PD-1 inhibitor-related cardiac dysfunction. The histopathological evaluation revealed that macrophages infiltrated in the cardiac tissue after ICIs treatment. ${ }^{37}$ Macrophages are important cells that modulate inflammation. Indeed, under some circumstance, macrophages promote inflammation and extend injury, thus leading to cardiac senescence-related injury. ${ }^{38}$ Previous studies suggested that exogenous stimuli-activated M1 macrophages induced resident cell injury through exosomal miR delivery. ${ }^{21}$ This study showed that treatment with exosomes from PD-1 inhibitor-treated macrophages increased the levels of miR-34a-5p in cardiomyocytes. The results showed a correlation between the levels of miR-34a-5p transferred to cardiomyocytes and cellular senescence. These results confirmed the hypothesis that the PD-1 inhibitor induced cardiac injury through macrophage-derived exosome transfer.

miRs, short endogenous strands of RNAs of 18-24 nucleotides in length, are post-transcriptional regulators of gene expression. ${ }^{39}$ Microarray profiling analyses in our 
present study identified differentially expressed miRs in PD-1 inhibitor treated and normal mice hearts, most of which has been identified with crucial role in cardiac function. The miR-221/222 family is one of the first miRNA families found to be associated with cardiac fibrosis and immune-related cardiomyopathy. ${ }^{41}$ Researchers also identify a heart failure-dependent increase in miR-145 expression in human hearts and uncover the role of miR-145 in promoting cell senescence. ${ }^{42}$ The role of miR-34a in regulating cell senescence, development, and vitality has been extensively highlighted in a variety of cells. ${ }^{43}$ Also, miR-34a can be profoundly impacted by immune signaling. ${ }^{44}$ This study found that ICIs induced the accumulation of miR-34a-5p in the exosomes and its transfer to cardiomyocytes, thus leading to cardiac senescence. miR-34 has been reported to promote cell cycle arrest, ${ }^{45}$ coincident with the finding of the present study that exosomal-delivered miR-34a-5p inhibited cell cycle in the G0/G1 phase. miR-34a triggers senescence partly through the genetic inhibition of PNUTS in cardiomyocytes. ${ }^{46}$ This observation led to the exploration of the potential role of a PD-1 inhibitor in modulating miR34a-dependent PNUTS expression in cardiomyocytes. The results showed that exosome $\mathrm{P}^{\mathrm{PD}-1 \text { inhibitor }}$ significantly promoted miR-34a-5p transfer but inhibited PNUTS in cardiomyocytes. A study of the mechanistic role of miR$34 \mathrm{a}$ in regulating cardiac function unveiled PNUTS as a target of miR-34a, which was downregulated with age. ${ }^{47}$ PNUTS has emerged as a component of the DNA damage response that is recruited to DNA damage sites and inhibits cell cycle arrest, ${ }^{48}$ which was consistent with the findings of the present study that enforcing PNUTS expression relieved the cell cycle arrest caused by exosome ${ }^{\mathrm{PD}-1}$ inhibitor. PNUTS interacted with telomere regulator, alleviating DNA damage-related telomere shortening and thus conferring a protective effect. ${ }^{49}$ Interestingly, the downregulation of the expression of PNUTS gene and protein induced by exosome $\mathrm{PD}^{\mathrm{PD}-1 \text { inhibitor }}$ was accompanied by telomere length shortening in cardiomyocytes.

Some limitations existed in the current study. PD-1 inhibitor-related cardiotoxicity was only explored in animal model. Clinical experiments to demonstrate relationship between the miR-34a-5p levels and immunotherapy-related cardiotoxicity will carry on in the future. Meanwhile, miR-34a-5p knock-out (KO) animal will be applied to confirm our findings in the future study.

\section{CONCLUSIONS}

This study provided compelling evidence for the role of a PD-1 inhibitor in inducing cardiac senescence that accounted for cardiac injury. The exosomes derived from PD-1 inhibitor-treated macrophages markedly promoted cardiomyocyte senescence. The associated mechanism was also deciphered; specifically, exosomes transferred miR-34a-5p, leading to the inhibition of PNUTS in cardiomyocytes, thereby resulting in cardiac senescence. These findings might provide a new target in ameliorating cardiac injury in patients receiving immunotherapy.

\section{Author affiliations}

${ }^{1}$ Neurosurgery, Wenzhou Medical University First Affiliated Hospital, Wenzhou, Zhejiang, China

${ }^{2}$ Neurosurgery, Xinhua Hospital Affiliated to Shanghai Jiaotong University School of Medicine, Shanghai, China

${ }^{3}$ Radiation Oncology, First Affiliated Hospital, Wenzhou Medical University, Wenzhou, China

Acknowledgements We thank Professor Fengming Kong for her expert assistance with experimental design and excellent technical assistance. We thank Dr Huijia Zhu for her expert assistance with echo experimental design and excellent technical assistance.

Contributors WZX, HBC and DDC made substantial contributions to the acquisition of data, analysis and interpretation of data, conception and design; YJY made substantial contributions to the acquisition of data, analysis in the revision process; CYX participated in revising the article critically for important intellectual content; drafting the article; MH was involved in conception and design of the study, drafting and revising the manuscript.

Funding The present study was supported by he National Natural Science Foundation of China (grant nos. 82071561 to MH); the Science and Technology Planning Project of Wenzhou (grant no. Y2020735 to MH); and the Medical Science and Technology Project of Zhejiang Province (grant no. 2018KY517 to MH).

Competing interests None declared.

Patient consent for publication Not required.

Ethics approval All study procedures were approved by the Institutional Animal Care and Use Committee of Wenzhou Medical University (IRB approval number: WYDW 2019-0491).

Provenance and peer review Not commissioned; externally peer reviewed. Data availability statement Data are available upon reasonable request.

Supplemental material This content has been supplied by the author(s). It has not been vetted by BMJ Publishing Group Limited (BMJ) and may not have been peer-reviewed. Any opinions or recommendations discussed are solely those of the author(s) and are not endorsed by BMJ. BMJ disclaims all liability and responsibility arising from any reliance placed on the content. Where the content includes any translated material, BMJ does not warrant the accuracy and reliability of the translations (including but not limited to local regulations, clinical guidelines, terminology, drug names and drug dosages), and is not responsible for any error and/or omissions arising from translation and adaptation or otherwise.

Open access This is an open access article distributed in accordance with the Creative Commons Attribution Non Commercial (CC BY-NC 4.0) license, which permits others to distribute, remix, adapt, build upon this work non-commercially, and license their derivative works on different terms, provided the original work is properly cited, appropriate credit is given, any changes made indicated, and the use is non-commercial. See http://creativecommons.org/licenses/by-nc/4.0/.

ORCID iD

Meng Hou http://orcid.org/0000-0002-6304-724X

\section{REFERENCES}

1 Sondak VK, McArthur GA. Adjuvant immunotherapy for cancer: the next step. Lancet Oncol 2015;16:478-80.

2 Mahmood SS, Fradley MG, Cohen JV, et al. Myocarditis in patients treated with immune checkpoint inhibitors. J Am Coll Cardiol 2018;71:1755-64.

3 Johnson DB, Balko JM, Compton ML, et al. Fulminant myocarditis with combination immune checkpoint blockade. N Engl J Med 2016;375:1749-55

4 Ganatra S, Neilan TG. Immune checkpoint inhibitor-associated myocarditis. Oncologist 2018;23:879-86.

5 Heinzerling L, Ott PA, Hodi FS, et al. Cardiotoxicity associated with CTLA4 and PD1 blocking immunotherapy. J Immunother Cancer 2016;4:50.

6 Neilan TG, Rothenberg ML, Amiri-Kordestani L, et al. Myocarditis associated with immune checkpoint inhibitors: an expert consensus on data gaps and a call to action. Oncologist 2018;23:874-8. 
7 Wagner JUG, Dimmeler S. Cellular cross-talks in the diseased and aging heart. J Mol Cell Cardiol 2020;138:136-46.

8 Swirski FK, Nahrendorf M. Cardioimmunology: the immune system in cardiac homeostasis and disease. Nat Rev Immunol 2018;18:733-44.

9 Ramos GC, van den Berg A, Nunes-Silva V, et al. Myocardial aging as a T-cell-mediated phenomenon. Proc Natl Acad Sci U S A 2017:114:E2420-9.

10 McManus DD, Xanthakis V, Sullivan LM, et al. Longitudinal tracking of left atrial diameter over the adult life course: clinical correlates in the community. Circulation 2010;121:667-74.

11 Lavin Y, Winter D, Blecher-Gonen R, et al. Tissue-resident macrophage enhancer landscapes are shaped by the local microenvironment. Cell 2014;159:1312-26.

12 Sager HB, Hulsmans M, Lavine KJ, et al. Proliferation and recruitment contribute to myocardial macrophage expansion in chronic heart failure. Circ Res 2016;119:853-64.

13 Tajiri K, leda M. Cardiac complications in immune checkpoint inhibition therapy. Front Cardiovasc Med 2019;6:3

14 Tavakoli Dargani Z, Singla DK. Embryonic stem cell-derived exosomes inhibit doxorubicin-induced TLR4-NLRP3-mediated cell death-pyroptosis. Am J Physiol Heart Circ Physiol 2019;317:H460-71.

15 Bell Courtnee' R, Jones LB, Crenshaw BJ, et al. The role of lipopolysaccharide-induced extracellular vesicles in cardiac cel death. Biology 2019;8:69.

16 Govindappa PK, Patil M, Garikipati VNS, et al. Targeting exosomeassociated human antigen $\mathrm{R}$ attenuates fibrosis and inflammation in diabetic heart. Faseb J 2020;34:2238-51.

17 Goulielmaki E, loannidou A, Tsekrekou M, et al. Tissue-infiltrating macrophages mediate an exosome-based metabolic reprogramming upon DNA damage. Nat Commun 2020:11:42.

18 Ooi JYY, Bernardo BC, Singla S, et al. Identification of miR-34 regulatory networks in settings of disease and antimiR-therapy: implications for treating cardiac pathology and other diseases. RNA Biol 2017;14:500-13.

19 Emanueli C, Thum T. miRNAGE-34 induces cardiac damAGE. Cell Res 2013;23:866-7.

20 Tkach M, Théry C. Communication by extracellular vesicles: where we are and where we need to go. Cell 2016;164:1226-32.

21 Liu X-L, Pan Q, Cao H-X, et al. Lipotoxic hepatocyte-derived exosomal microRNA 192-5p activates macrophages through Rictor/ Akt/Forkhead box transcription factor $\mathrm{O} 1$ signaling in nonalcoholic fatty liver disease. Hepatology 2020;72:454-69.

22 Filippi-Chiela EC, Silva MMBe, Thomé MP, et al. Single-Cell analysis challenges the connection between autophagy and senescence induced by DNA damage. Autophagy 2015;11:1099-113.

23 Chen $\mathrm{H}$, Xia W, Hou M. LncRNA-NEAT1 from the competing endogenous RNA network promotes cardioprotective efficacy of mesenchymal stem cell-derived exosomes induced by macrophage migration inhibitory factor via the miR-142-3p/FOXO1 signaling pathway. Stem Cell Res Ther 2020;11:31

24 Raso A, Dirkx E, Philippen LE, et al. Therapeutic delivery of miR148a suppresses ventricular dilation in heart failure. Mol Ther 2019;27:584-99.

25 Woods DM, Ramakrishnan R, Laino AS, et al. Decreased suppression and increased phosphorylated STAT3 in regulatory T cells are associated with benefit from adjuvant PD-1 blockade in resected metastatic melanoma. Clin Cancer Res 2018;24:6236-47.

26 Carlson S, Helterline D, Asbe L, et al. Cardiac macrophages adopt profibrotic/M2 phenotype in infarcted hearts: role of urokinase plasminogen activator. J Mol Cell Cardiol 2017;108:42-9.

27 Crepin T, Carron C, Roubiou C, et al. ATG-induced accelerated immune senescence: clinical implications in renal transplant recipients. Am J Transplant 2015;15:1028-38.
28 Xie Z, Xia W, Hou M. Long intergenic non-coding RNA-p21 mediates cardiac senescence via the $W n t / \beta$-catenin signaling pathway in doxorubicin-induced cardiotoxicity. Mol Med Rep 2018;17:2695-704.

$29 \mathrm{Yu} \mathrm{D}, \mathrm{An} \mathrm{X}$, Fan W, et al. Pnuts mediates ionizing radiation-induced CNE-2 nasopharyngeal carcinoma cell migration, invasion, and epithelial-mesenchymal transition via the PI3K/Akt signaling pathway. Onco Targets Ther 2019;12:1205-14

30 Awadalla M, Mahmood SS, Groarke JD, et al. Global longitudinal strain and cardiac events in patients with immune checkpoint Inhibitor-Related myocarditis. J Am Coll Cardiol 2020;75:467-78.

31 Postow MA, Callahan MK, Wolchok JD. Immune checkpoint blockade in cancer therapy. J Clin Oncol 2015;33:1974-82.

32 Palaskas N, Lopez-Mattei J, Durand JB, et al. Immune checkpoint inhibitor myocarditis: pathophysiological characteristics, diagnosis, and treatment. J Am Heart Assoc 2020;9:e013757.

33 Lakatta EG. Arterial and cardiac aging: major shareholders in cardiovascular disease enterprises: Part III: cellular and molecular clues to heart and arterial aging. Circulation 2003;107:490-7.

34 Jeyapalan JC, Sedivy JM. Cellular senescence and organismal aging. Mech Ageing Dev 2008;129:467-74.

35 Shay JW, Wright WE. Role of telomeres and telomerase in cancer. Semin Cancer Biol 2011;21:349-53.

36 Rastogi S, Hwang A, Chan J, et al. Extracellular vesicles transfer nuclear Abl-dependent and radiation-induced miR-34c into unirradiated cells to cause bystander effects. Mol Biol Cell 2018;29:2228-42.

$37 \mathrm{Ji} \mathrm{C}$, Roy MD, Golas J, et al. Myocarditis in cynomolgus monkeys following treatment with immune checkpoint inhibitors. Clin Cancer Res 2019;25:4735-48.

38 Hu D, Dong R, Yang Y, et al. Human kallikrein overexpression alleviates cardiac aging by alternatively regulating macrophage polarization in aged rats. Faseb $\mathrm{J}$ 2019;33:8436-52.

39 Noren Hooten N. Fitzpatrick M, Wood WH, et al. Age-Related changes in microRNA levels in serum. Aging 2013;5:725-40.

40 Verjans R, Peters T, Beaumont FJ, et al. Microrna-221/222 family counteracts myocardial fibrosis in pressure overload-induced heart failure. Hypertension 2018;71:280-8.

41 Corsten MF, Heggermont W, Papageorgiou A-P, et al. The microRNA-221/-222 cluster balances the antiviral and inflammatory response in viral myocarditis. Eur Heart J 2015;36:2909-19.

42 Zhang M, Cheng Y-J, Sara JD, et al. Circulating microRNA-145 is associated with acute myocardial infarction and heart failure. Chin Med J 2017;130:51-6.

43 Zhao T, Li J, Chen AF. Microrna-34A induces endothelial progenitor cell senescence and impedes its angiogenesis via suppressing silent information regulator 1. Am J Physiol Endocrinol Metab 2010;299:E110-6.

44 Xiong X-P, Kurthkoti K, Chang K-Y, et al. miR-34 modulates innate immunity and ecdysone signaling in Drosophila. PLoS Pathog 2016;12:e1006034.

45 Feng $\mathrm{H}$, Ge F, Du L, et al. MiR-34b-3p represses cell proliferation, cell cycle progression and cell apoptosis in non-small-cell lung cancer (NSCLC) by targeting CDK4. J Cell Mol Med 2019;23:5282-91.

46 Dorn GW. miR-34A and the cardiomyopathy of senescence: salt PNUTS, salt PNUTS! Cell Metab 2013;17:629-30.

47 Loffredo FS, Pancoast JR, Lee RT. Keep PNUTS in your heart. Circ Res 2013;113:97-9.

48 Boon RA, lekushi K, Lechner S, et al. Microrna-34A regulates cardiac ageing and function. Nature 2013;495:107-10.

49 Landsverk HB, Mora-Bermúdez F, Landsverk OJB, et al. The protein phosphatase 1 regulator PNUTS is a new component of the DNA damage response. EMBO Rep 2010;11:868-75. 